\title{
A randomised study of two training programmes for general practitioners in the techniques of shoulder injection
}

\author{
G J Gormley, W K Steele, M Stevenson, R McKane, I Ryans, A P Cairns, A Pendleton, \\ G D Wright, A J Taggart
}

Ann Rheum Dis 2003;62:1006-1009

Objectives: To evaluate the impact of two different modes of shoulder injection training on the level of confidence and number of injections performed by general practitioners (GPs)

Methods: Demographic details, and information on referrals for shoulder problems, shoulder joint injection activity, and confidence in the six months before training were obtained for 40 GP principals at baseline. Standardised training in the techniques of shoulder joint injection using rubber mannequins was given to all GPs. Twenty of these GPs were randomly allocated to receive additional training on patients in hospital joint injection clinics. Six months after both forms of training the shoulder injection and referral activities of all GPs were reassessed.

Results: Both training groups had comparable demographic characteristics and baseline clinical activity. GPs who had additional training with patients reported a marked increase in their level of confidence in performing shoulder injections and the number performed. The number of shoulder referrals did not differ between the groups

Conclusion: Training on patients in addition to conventional training on mannequins increased $\mathrm{GPs}^{\prime}$ shoulder injection activity and their level of confidence. Hospital injection clinics may provide a suitable setting in which to train GPs interested in developing their shoulder joint injection skills.

S houlder disorders are a common reason for consulting a general practitioner (GP). ${ }^{12}$ For many shoulder conditions, treatment often consists of non-steroidal antiinflammatory drugs, physiotherapy, or corticosteroid injection. Corticosteroid injections often bring about a rapid and effective response, with few complications. ${ }^{3-6}$ In a recent survey of joint injection practices amongst GPs, shoulder injections were the commonest type of injection performed in the community. ${ }^{7}$ Procedures carried out by GPs in the community have also been shown to be cost effective and popular with patients. ${ }^{8}$

Training using shoulder mannequins is the most commonly used teaching method. ${ }^{7}$ A considerable number of GPs trained by this method do not currently perform injections on patients. ${ }^{7}$ A minority of GPs have trained on patients, and there is a significant correlation between this teaching method and current injection activity.?

This study aimed at evaluating the impact of two different methods of shoulder injection training on the reported number of injections performed by GPs and their level of confidence in carrying them out.

\section{SUBJECTS AND METHODS \\ Subjects}

GP principals in the Northern Ireland Eastern Health and Social Services Board $(n=432)$ were invited to apply for a training course in joint injection techniques. Power calculations indicated that 40 GPs would be required to show a difference of one standard deviation, with a $90 \%$ power in each of the outcome variables. The first 44 applicants were given course places. Inclusion criteria required that participating GPs were principals and willing to receive extended training on patients, in addition to mannequins, if selected.

\section{Baseline assessment}

Before the training course, selected GPs recorded their demographic characteristics, duration in practice, and previous experience in performing shoulder injections in a postgraduate training post (for example, rheumatology, orthopaedics, or sports medicine). Participants were asked to review their records and document:

- The number of shoulder injections that they had performed in the six months before the training course

- Their level of confidence (on a $10 \mathrm{~cm}$ visual analogue scale) in performing shoulder joint injections.

- The number of patients with shoulder complaints that they had referred to hospital injection clinics or physiotherapy in the six months before the training course.

\section{Training}

All participating GPs attended a one day training course held at Musgrave Park Hospital, Belfast. Training on shoulder injection techniques included:

- A lecture on shoulder anatomy and assessment

- Work in small groups on shoulder assessment

- A lecture on shoulder injection techniques

- Work in small groups on shoulder injection techniques, using rubber mannequins.

The work in small groups was supervised by rheumatologists in a ratio of five GPs to one rheumatologist. Before training, all rheumatologists were briefed by the course organisers to standardise the method of training. The shoulder injection techniques taught by each rheumatologist reflected their own clinical practice and focused on anterior, posterior, and lateral shoulder injections. The training was carried out in stages. First the GP watched their tutor injecting the shoulder mannequin, then discussed details of the injection technique with the tutor, and finally, demonstrated their own injection technique to their tutor.

When all the GPs had been trained on shoulder mannequins, they were then told who would receive further training on patients. Half of the GPs participating in the study were 
Table 1 GPs' demographic characteristics and reported clinical activity before training

\begin{tabular}{|c|c|c|c|}
\hline & $\begin{array}{l}\text { GPs who trained on } \\
\text { patients + mannequins }\end{array}$ & $\begin{array}{l}\text { GPs who trained on } \\
\text { mannequins only }\end{array}$ & $\mathrm{p}$ Value \\
\hline \multicolumn{4}{|l|}{ Sex } \\
\hline Male & 15 & 14 & \multirow{2}{*}{1.00} \\
\hline Female & 5 & 6 & \\
\hline \multicolumn{4}{|l|}{ Duration in practice (years) } \\
\hline $1-5$ & 4 & 6 & \multirow{4}{*}{0.38} \\
\hline $6-10$ & 2 & 3 & \\
\hline $11-20$ & 10 & 8 & \\
\hline $21-29$ & 4 & 3 & \\
\hline \multicolumn{4}{|c|}{ Previous post in rheumatology, orthopaedic, or sports medicine } \\
\hline Yes & 2 & 1 & \multirow{2}{*}{1.0} \\
\hline No & 18 & 19 & \\
\hline \multicolumn{4}{|c|}{ Reported clinical activity in six months before training } \\
\hline Shoulder injections performed & 3.4 & 3.5 & 0.94 \\
\hline Referrals to injection clinics & 2.0 & 2.3 & 0.75 \\
\hline Referrals to physiotherapy & 5.6 & 5.9 & 0.79 \\
\hline \multicolumn{4}{|c|}{ Level of confidence in performing shoulder injections before training } \\
\hline Mean score on $10 \mathrm{~cm}$ VAS* & 3.9 & 4.1 & 0.79 \\
\hline
\end{tabular}

Table 2 Comparison of degree of change in reported clinical activity in the six months after training, between each mode of training

\begin{tabular}{|c|c|c|c|c|}
\hline & $\begin{array}{l}\text { Mean change } \\
\text { after training }\end{array}$ & $\begin{array}{l}\text { Change in variable after } \\
\text { patient training - change } \\
\text { in variable after } \\
\text { mannequin training }\end{array}$ & p Value & $95 \% \mathrm{Cl}$ \\
\hline \multicolumn{5}{|l|}{ Reported number of shoulder injections performed after } \\
\hline Additional training on patients & 4.4 & 3.4 & 0.02 & 0.6 to 6.1 \\
\hline Mannequin training & 1.0 & & & \\
\hline \multicolumn{5}{|l|}{ Reported shoulder referral activity to } \\
\hline Injection clinics after additional training on patients & -1.4 & -0.51 & 0.36 & -1.6 to 0.6 \\
\hline Injection clinics after training on mannequins & -0.8 & & & \\
\hline Physiotherapy after additional training on patients & -2.4 & -1.2 & 0.20 & -3.2 to 0.7 \\
\hline Physiotherapy after mannequin training & -1.2 & & & \\
\hline \multicolumn{5}{|l|}{ *Level of confidence after } \\
\hline Additional training on real patients & 3.6 & 2.3 & $<0.01$ & 0.9 to 3.7 \\
\hline Mannequin training & 1.4 & & & \\
\hline
\end{tabular}

randomly selected to receive this additional training, which took place at two hospital injection clinics (Musgrave Park and Belfast City Hospitals). At these sessions (lasting for three hours), GPs received further training and hands on experience in shoulder joint injection techniques on patients who had been referred with shoulder complaints. Training was supervised by rheumatologists, who had met previously to standardise their method of teaching. The approach was similar to that used during the mannequin training day. ${ }^{9}$

\section{Assessment after training}

Six months after training, each GP was asked to record:

- The number of shoulder injections performed since training

- Their current level of confidence in performing shoulder injections

- The number of patients with shoulder complaints that they had referred to hospital injection clinics or physiotherapy since training.

\section{Statistical analysis}

Fisher's exact test was used to assess the comparability of the demographic characteristics and self reported clinical activity of the two groups before training. An independent samples $t$ test was used to compare the degree of change in self reported clinical activity after training. Spearman's rank correlation was used to evaluate the association between GPs' level of confidence in performing injections and the reported number of injections before training.

\section{Ethical approval}

The study was approved by the Queen's University of Belfast Research ethics committee (application No 85/01). Consent was obtained both from GPs and patients who participated in the additional training sessions of the study.

\section{RESULTS}

Forty four GPs were allocated places in the training course, but two cancelled and two did not attend on the day. Thus 40 GPs took part in the study. One GP's assessment return after training was incomplete and another failed to make a return. Both of these GPs were in the "mannequin only" training group.

Table 1 shows the demographic characteristics and baseline clinical activity of the two training groups, which were comparable.

There was a significant correlation between GPs' level of confidence in performing shoulder injections before training and the number of injections performed before training (fig 1).

Table 2 compares the degree of change in self reported clinical activity after training in the two groups. GPs who had additional training with patients reported a significantly greater increase in the number of shoulder injections and level of confidence in performing injections than those who were trained on mannequins only. No difference was found in the number of shoulder referrals to either hospital injection clinics or to physiotherapy between the groups. 


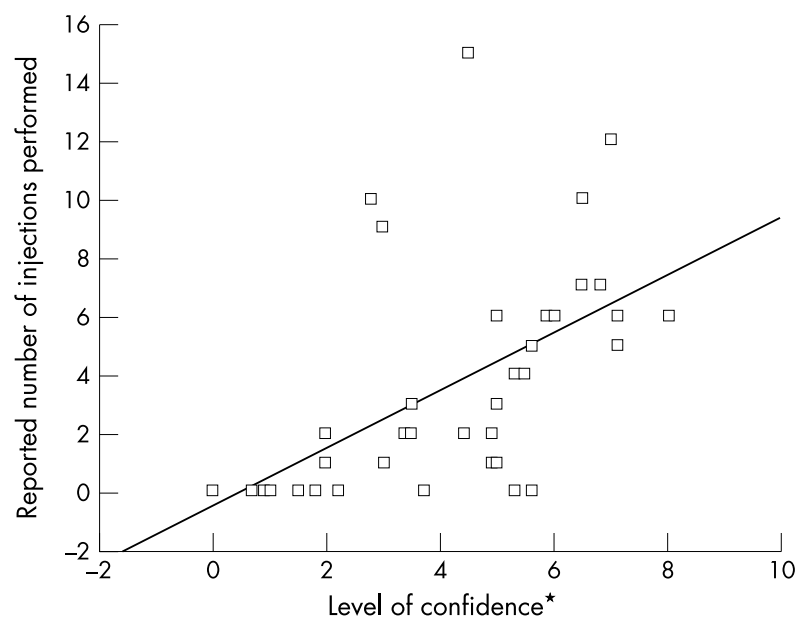

Figure 1 Correlation of the level of confidence in performing shoulder injections before training and the number of reported shoulder injections performed before training (all GPs).

\section{DISCUSSION}

This paper describes a randomised trial comparing the impact of two training programmes for GPs in the skills of shoulder joint injection on the number of injections performed by GPs and their level of confidence in carrying them out. GPs who received training on patients as well as rubber mannequins subsequently performed greater numbers of shoulder joint injections with more confidence than those who were trained on mannequins alone. These findings are in keeping with the results of our postal survey of GPs' attitudes towards joint injection training. ${ }^{7}$

Though training on shoulder mannequins had a positive impact on GPs' injection activity, the additional experience gained with patients had a demonstrable impact on the trainees' shoulder injection activity and levels of confidence. This may simply have been the result of the additional time devoted to injection training, but the GPs, at the end of the study felt that the experience of injecting patients was an important factor.

Our findings also indicate that there was no significant difference between the two modes of training in the amount of reported shoulder referrals to either hospital injection clinics or physiotherapy. This may merely reflect the small sample size or the fact that several variables, including patient, doctor, and healthcare system factors, may influence referral patterns from primary to secondary care. ${ }^{10}$

To date, only a small minority of GPs have trained on patients. ${ }^{7}$ Given the positive findings of this study, we believe that training on patients in shoulder injection skills should be encouraged for GPs. The natural place for such training is the hospital injection clinic, but the efficiency of that service might be impaired by large numbers of GP training sessions.

The main perceived barrier to performing injections in the community is the inability to maintain injection skills. ${ }^{7}$ Because a minority of GPs perform the majority of injections in the community, ${ }^{7}$ perhaps the efforts of rheumatologists should be focused on training those GPs who are interested in developing their injection skills and, in particular, those with a specialist interest in rheumatology. The NHS plan aims to modernise healthcare provision and promote GPs with special interests. ${ }^{11}$ Rheumatologists have an opportunity to encourage these developments in primary care and joint injection training is just one skill that can usefully be shared with our GP colleagues. ${ }^{12}$ A proportion of hospital injection clinics could be designated for GP training and the appraisal of GPs with special interests who perform injections in the community. Joint and soft tissue injections are not recommended as a core activity in the curriculum of GP registrars, but those who express an interest in performing injections should be offered the chance to train on patients. ${ }^{13}$

Values used in this study were self reported and recorded by the participating GPs and not verified independently. Nevertheless, the analysis used in this study was based on the difference in change of reported clinical activity rather than absolute values. Therefore, as all the GPs received mannequin training, and only learnt after this training which of them would train on patients, we would be hopeful that the "halo" effect would be accounted for by examining the difference of change in both groups.

We have not attempted to assess the impact of different training methods on the clinical benefits of shoulder joint injection by GPs in the community. We are aware that intra-articular injection is often inaccurate (even by trained rheumatologists) and that this may have some impact on the recovery of symptoms. However, given the positive findings of this study, such an evaluation of the impact of different training methods on clinical outcomes would be worthy of future research. ${ }^{14-16}$ Equally, we acknowledge that GPs confidence, as measured in this study, may correlate with perceived levels of self efficacy that may not directly relate to clinical performance.

In conclusion, training on patients in addition to conventional training on model mannequins improves GPs' shoulder injection activity and level of confidence over a six month period. Hospital injection clinics provide a suitable place in which to train and assess those GPs with special interest in performing joint injections in the community.

\section{ACKNOWLEDGEMENTS}

We are grateful to the Stone Forum for clinical support for this study. We thank Dr Michael Finch, Dr Gary Meenagh, Dr Anita Smyth, and Miss Mary Clifford for their support with this study and all the general practitioners who participated in this study.

\section{Authors' affiliations}

G J Gormley, W K Steele, Department of General Practice, Queens University, Belfast, Northern Ireland

M Stevenson, Department of Epidemiology, Queens University, Belfast, Northern Ireland

R McKane, I Ryans, Department of Rheumatology, Ulster Hospital, Dundonald, Belfast, Northern Ireland

A P Cairns, A Pendleton, G D Wright, A J Taggart, Department of Rheumatology, Musgrave Park Hospital, Belfast, Northern Ireland

Correspondence to: Dr G J Gormley, Department of General Practice, Queens University Belfast, Dunluce Health Centre, 1 Dunluce Avenue, Belfast, Northern Ireland BT9 7HR, UK;

gerry@teamgormley.freeserve.co.uk

Accepted 17 February 2003

\section{REFERENCES}

1 Van der Windt DAWN, Koes BW, De Jong BA, Bouter LM. Shoulder disorders in general practice: incidence, patient characteristics and management. Ann Rheum Dis 1995;54:959-64

2 Croft P. Soft tissue rheumatism. In: Silman AJ, Hochberg MC, eds Epidemiology of the rheumatic diseases. Oxford: Oxford Medical Publications, 1993:375-421.

3 Winters JC, Sobel JS, Groenier KH, Ardenzen HJ, Meyboom-de Jong B. Comparison of physiotherapy, manipulation and corticosteroid injection for treating shoulder complaints in general practice: randomized single blind study. BM 1997;317:1292-6.

4 Van der Windt DAWN, Koes BW, Deville W, Boeke AJP, de Jong BA, Bouter LM. Effectiveness of corticosteroid injections versus physiotherapy for treatment of painful stiff shoulder in general practice: randomized trail. Br J Gen Pract 1996;46:309-16.

5 Blair B, Rokito AS, Cuomo F, Jarolem K, Zuckerman JD. Efficacy of injections of corticosteroids for subacromial impingement syndrome. J Bone Joint Surg Am 1996;78:1685-9.

6 Kumar N, Newman RJ. Complications of intra- and peri-articular steroid injections. Br J Gen Pract 1999;49:465-6.

7 Gormley G, Steele WK, Corrigan M, Stevenson M, Taggart AJ. Joint and soft tissue injections in the community - Questionnaire survey of general practitioners' experiences and attitudes. Ann Rheum Dis (in press).

8 Brown JS, Smith RR, Cantor T, Chesover D, Yearsley R. General practitioners as providers of minor surgery-a success story?. Br J Gen Pract 1997;47:205-10. 
9 Ausubel D. Educational psychology: a cognitive view. New York: Holt, Rinerart and Winston, 1968

10 Wilkin D. Patterns of referral: explaining variation. In: Roland M, Coulter A, eds. Hospital referrals, Oxford: Oxford University Press, 1992. (Oxford General Practice Series 22.)

11 Secretary of State for Health. The NHS plan: a plan for investment, a plan for reform. London: Stationery Office, 2000.

12 Grahame R, Gibson T, Dale E, Anderson JAD, Brown R, Higgins P, et al. An evaluated programme of rheumatology training for general practitioners. Br J Rheumatol 1986;25:7-12.
13 ARD. Learning guide for general practitioners and general practice registrars on musculoskeletal problems. Chesterfield, Derbyshire: Arthritis Research Campaign, 2000.

14 Eustace JA, Brophy DP, Gibney RP, Bresnihan B, FitzGerald O. Comparison of the accuracy of steroid placement with clinical outcome in patients with shoulder symptoms. Ann Rheum Dis 1997;56:59-63.

15 Jones A, Regan M, Ledingham J, Pattrick M, Manhire A, Doherty M. Importance of steroid placement of intra-articular injections. BM 1993;307: 1329-30.

16 White, Tuite JD. The accuracy and efficacy of shoulder injections in restrictive capsulitis. J Orthop Rheumatol 1996;9:37-40.

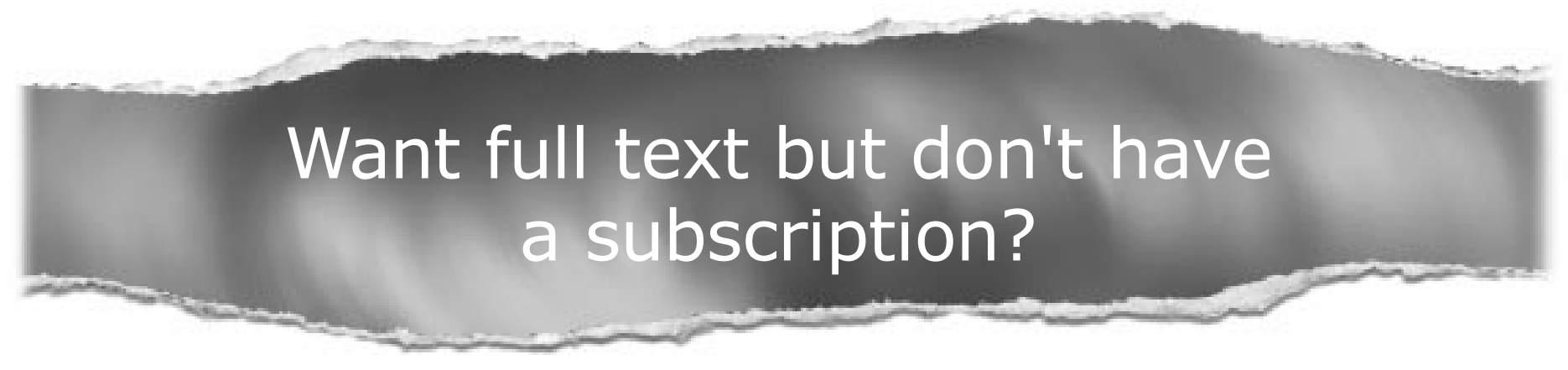

\section{Pay per view}

For just $\$ 8$ you can purchase the full text of individual articles using our secure online ordering service. You will have access to the full text of the relevant article for 48 hours during which time you may download and print the pdf file for personal use.

\section{www.annrheumdis.com}

